\title{
Comparing surgically induced astigmatism calculated by means of simulated keratometry versus total corneal refractive power
}

European Journal of Ophthalmology I-9

(C) The Author(s) 2018 Reprints and permissions: sagepub.co.uk/journalsPermissions.nav DOI: | 0.1 | 777/| | 20672| | 8757666 journals.sagepub.com/home/ejo (\$SAGE

\author{
Nuria Garzón', Manuel Rodríguez-Vallejo², David Carmona ${ }^{3}$, \\ Jorge A Calvo-Sanz ${ }^{4}$, Francisco Poyales', Carlos Palomino ${ }^{3}$, \\ Miguel Á Zato-Gómez de Liaño ${ }^{4}$ and Joaquín Fernández ${ }^{2,5}$
}

\begin{abstract}
Purpose: To evaluate surgically induced astigmatism as computed by means of either simulated keratometry $\left(\mathrm{K}_{\mathrm{SIM}}\right)$ or total corneal refractive power (TCRP) after temporal incisions.

Methods: Prospective observational study including 36 right eyes undergoing cataract surgery. Astigmatism was measured preoperatively during the 3-month follow-up period using Pentacam. Surgically induced astigmatism was computed considering anterior corneal surface astigmatism at $3 \mathrm{~mm}$ with $\mathrm{K}_{\mathrm{SIM}}$ and considering both corneal surfaces with TCRP from I to $8 \mathrm{~mm}\left(\mathrm{TCRP}_{3}\right.$ for $\left.3 \mathrm{~mm}\right)$. The eyes under study were divided into two balanced groups: LOW with $\mathrm{K}_{\mathrm{SIM}}$ astigmatism $<0.90 \mathrm{D}$ and $\mathrm{HIGH}$ with $\mathrm{K}_{\mathrm{SIM}}$ astigmatism $\geq 0.90 \mathrm{D}$. Resulting surgically induced astigmatism values were compared across groups and measuring techniques by means of flattening, steepening, and torque analysis.

Results: Mean surgically induced astigmatism was higher in the HIGH group $\left(0.31 \mathrm{D} @ 102^{\circ}\right)$ than in the LOW group $\left(0.04 \mathrm{D} @ 16^{\circ}\right)$. The temporal incision resulted in a steepening in the HIGH group of $0.15 \mathrm{D} @ 90^{\circ}$, as estimated with $\mathrm{K}_{\mathrm{SIM}}$, versus $0.28 \mathrm{D} @ 90^{\circ}$ with $\mathrm{TCRP}_{3}$, but no significant differences were found for the steepening in the LOW group or for the torque in either group. Differences between $\mathrm{K}_{\mathrm{SIM}^{-}}$and $\mathrm{TCRP}_{3}$-based surgically induced astigmatism values were negligible in LOW group.

Conclusion: Surgically induced astigmatism was considerably higher in the high-astigmatism group and its value was underestimated with the $\mathrm{K}_{\mathrm{SIM}}$ approach. Eyes having low astigmatism should not be included for computing the surgically induced astigmatism because steepening would be underestimated.
\end{abstract}

\section{Keywords}

Astigmatism, cataract surgery, posterior cornea, multifocal intraocular lens, surgically induced astigmatism

Date received: $X X X X$; accepted: $X X X X$

\section{Introduction}

Cataract surgery is one of the most widely performed ophthalmologic surgical procedures. ${ }^{1}$ It not only pursues the removal of the opacified lens but also achieves perfect vision for the patient. ${ }^{2}$

More than $30 \%$ of the eyes have corneal astigmatism that exceeds 1.0 diopter (D); this refractive error should be corrected during cataract surgery. ${ }^{3,4}$

It is well known that posterior corneal astigmatism plays an important role in total astigmatism,, 5 but way too often only anterior astigmatism is measured to

\footnotetext{
IInnova Ocular IOA Madrid, Madrid, Spain

2Department of Ophthalmology (Qvision), Vithas Virgen del Mar Hospital, Almería, Spain

${ }^{3}$ Hospital Universitario Quironsalud Madrid, Madrid, Spain

${ }^{4}$ Instituto de Ciencias Visuales, Madrid, Spain

${ }^{5}$ Department of Ophthalmology, Torrecárdenas Hospital Complex, Almería, Spain
}

Corresponding author:

Nuria Garzón, Innova Ocular IOA Madrid, c/ Galileo I04, Madrid 28003, Spain.

Email: ngarzon@ioamadrid.com 
calculate the power of the toric intraocular lens (IOL) to be implanted.

The incision that is required for IOL implantation during cataract surgery induces astigmatism - this is referred to as surgically induced astigmatism (SIA) - so the total amount of astigmatism to be corrected with the toric IOL must consider the flattening (FE) or steepening (SE) effect on the meridian of the preoperative corneal astigmatism on which the IOL is going to be aligned. ${ }^{7}$ The SIA will depend on several factors, including incision type, location and size, and its design or architecture..$^{8-11}$

Keratometers and placido-disk-based topographers have been traditionally used to measure pre- and postoperative astigmatism, based on the assumption of a fixed anterior/posterior corneal ratio. Thus, with these techniques, it is not possible to discern between anterior or total corneal SIA. ${ }^{12}$ The use of ray-tracing technologyfrom the center to the peripheral cornea-would allow us to obtain more accurate data and to know total SIA. ${ }^{13}$

An accurate measurement of these astigmatism valuesboth preoperative and induced ones - is crucial for optimum surgical outcomes and patient satisfaction to be achieved, especially when the implanted lens is a multifocal IOL, since the presence of residual astigmatism disperses each point of focus resulting in multifocality failure. ${ }^{14}$

The various studies in the literature have drawn different conclusions: regarding SIA on the posterior surface of the cornea, Nemeth et al. ${ }^{15}$ suggested that it may play a significant role, while Klijn et al. ${ }^{16}$ reported that it had a negligible clinical relevance. Both studies evaluated eyes with an anterior corneal astigmatism lower than $1.00 \mathrm{D}$.

Thus, besides of the LOW preoperative astigmatism, the purpose of our study was to evaluate total SIA (obtained from TCRP) and anterior SIA (obtained from $\mathrm{K}_{\mathrm{SIM}}$ ) in patients who were split into two groups (LOW and HIGH) according to preoperative anterior corneal astigmatism. As a secondary outcome, we wanted to compare total SIA, as measured with ray tracing at different corneal chords, versus SIA yielded by a conventional method relying on a fixed anterior/posterior ratio at $3 \mathrm{~mm}$.

\section{Material and methods}

\section{Subjects}

A total of 36 right eyes from 36 patients undergoing cataract surgery at IOA Madrid Innova Ocular were included in this study.

Participants' inclusion criteria were being 18 years old or older, having cataractous eyes, regular astigmatism, no comorbidities, and the availability and willingness to comply with examination procedures.

Exclusion criteria were any corneal disease that might have an impact on corneal topography, dry-eye syndrome, a history of corneal surgery, and intraoperative or postoperative complications that could influence the resulting corneal curvature (e.g. incision suture and wound burnt). In addition, subjects requiring an IOL power $\geq 26.0 \mathrm{D}$ were excluded, as those lenses may require a larger than usual incision.

The included patients were divided into two groups: Group LOW ( $\mathrm{n}=18)$, comprising patients with anterior corneal astigmatism $<0.90 \mathrm{D}$, and Group HIGH $(\mathrm{n}=18)$, made up of patients with anterior corneal astigmatism $\geq 0.90 \mathrm{D}$ (as measured with a Pentacam system).

This study was approved by the local ethical committee. All patients read and signed the corresponding patient's consent form and the study was carried out in accordance with the Declaration of Helsinki.

\section{Surgical procedure}

All surgical procedures were performed by the same experienced surgeon (F.P.) under topical anesthesia, using the computer-assisted cataract surgery system CALLISTO $^{\circledR}$ eye from Zeiss' Cataract Suite markerless (Carl Zeiss, Jena, Germany). A 2.2-mm, angled $45^{\circ}$, bevel up Beaver ${ }^{\circledR}$ Xstar $^{\circledR}$ Safety Slit Knife (Beaver-Visitec International, Waltham, MA, USA) was used to create a $2.2-\mathrm{mm}$ selfsealing clear corneal incision at $180^{\circ}$ (temporal) and about $1 \mathrm{~mm}$ anterior to the limbus.

Next, a continuous curvilinear capsulorhexis of approximately $5.5 \mathrm{~mm}$ in diameter was created. Two ophthalmic viscosurgical devices (OVDs) were used during surgery: the cohesive Healon (Abbott Laboratories Inc., Abbot Park, IL, USA) and the dispersive Amvisc (Bausch \& Lomb Inc., Rochester, NY, USA). The chosen IOL was then implanted in the capsular bag aided by the single-use Accuject 2.2-1 Pinjection system (Medicel Accuject, PhysIOL, Liège, Belgium). Following IOL implantation, all traces of OVDs were removed. No sutures were required upon surgery completion. Neither intra- nor postoperative complications occurred in any patient.

\section{IOL description}

The IOL models implanted of this study (POD F and POD FT) are both aspheric trifocal diffractive IOLs manufactured by PhysIOL. They both have the exact same diffractive pattern and a similar refractive index, but the POD F is a spherical lens, while the POD FT is the toric counterpart. They have a double C-loop IOL with $5^{\circ}$ angulation.

\section{Patient assessment}

Patients were assessed preoperatively and at days 1, 7, 30, and 90 after surgery, but in this article, we only include the data collected at the 3-month (i.e. 90 days) post-operative follow-up visit. The examinations included refraction, slitlamp examination, fundus evaluation, biometry, posterior optical coherence tomography, and corneal topography. 
Corneal-curvature measurements were carried out with a Pentacam HR Topographer (Oculus, Wetzlar, Germany), which provides the flat and steep central radii in the 3-mm zone on the anterior corneal surface and the flat and the steep radii from both surfaces in the optical zones ranging from 1 to $8 \mathrm{~mm}$. The corneal power was then computed based on the keratometric index $\left(\mathrm{K}_{\mathrm{SIM}}\right)$ for the anterior $3 \mathrm{~mm}$ surface and the total corneal refractive power (TCRP) by ray-tracing considering both surfaces for each one of the diameters, ranging from 1.0 to $8.0 \mathrm{~mm} .{ }^{17}$ The keratometric index of refraction for the $\mathrm{K}_{\mathrm{SIM}}$ is 1.3375 . By convention, most keratometers use the refractive index of 1.3375 when calculating the dioptric power from the anterior radius assuming the cornea were a single refracting surface. However, it has been known that this keratometric index is not the best approximation for the physiological power of the cornea. Due to the contribution from the posterior surface and the refractive index of the cornea (n cornea $=1.376$ ), the true net power of the cornea which can be calculated using thick lens models or using exact ray-tracing is lower than the value reported by standard keratometry.[AQ: 1] Concerning the measurement of the TCRP, the light is refracted according to the correct refractive index (1.376/1.336), the slope of the surfaces, and the exact location of the refraction. This is necessary because the anterior and posterior surface have principal planes that are located slightly different due to corneal thickness. ${ }^{18}$

Once the corneal power had been estimated, the required IOL power was then computed using either Barrett II Universal or Barrett toric formulae with an optimized constant (119.02). The target refraction was calculated with the $\mathrm{K}_{\mathrm{SIM}}$ value. Finally, the IOL leading to a refraction closest to emmetropia was chosen.

\section{Statistical analysis}

The Student t-test was used to compare the LOW and HIGH groups, the Mann-Whitney U test for those variables that were not normally distributed, and Fisher's test for qualitative variables. Cohen's $\kappa$ was run to determine the level of agreement between $\mathrm{K}_{\mathrm{SIM}}$ and $\mathrm{TCRP}_{3}$ when it comes to classifying preoperative astigmatism. Paired result comparisons within the same group were conducted with the paired t-test or Wilcoxon-signed rank test. Normality was tested with the Shapiro-Wilk test in all the cases. A Friedman test and pairwise comparisons were performed with a Bonferroni correction for multiple comparisons to determine whether there were statistically significant differences between $\mathrm{K}_{\mathrm{SIM}}$ and the TCRP along several chord lengths for preoperative astigmatism assessment and SIA estimation. SPSS version 20 software (SPSS Inc, Chicago, IL, USA) was used for the statistical analysis. The Refractive Analysis toolbox for MATLAB $^{19}$ (R2009; MathWorks, Natick, MA, USA) was used for vector analy- sis by the Alpins method ${ }^{20}$ and plot representations according to the standard. ${ }^{21}$

\section{Results}

\section{Comparison between methods for preoperative astigmatism}

Patient demographics and baseline characteristics are summarized in Table 1. Age, axial length, and anteriorchamber depth were not significantly different between the two patient groups, whereas mean corneal power and corneal astigmatism were higher in the HIGH group. A lower agreement level (with the rule (WTR), against the rule (ATR), Oblique) between $\mathrm{K}_{\mathrm{SIM}}$ and $\mathrm{TCRP}_{3}$ was found in the LOW group $(\kappa=0.27, \mathrm{p}<0.09)$ versus the HIGH one $(\kappa=0.68, \mathrm{p}<0.001)$ and no significant differences were found between HIGH and LOW groups in the number of eyes classified according to each type of astigmatism (Table 2).

The preoperative mean corneal astigmatism was WTR (Figure 1). The WTR astigmatism was overestimated with the $\mathrm{K}_{\mathrm{SIM}}$ for both groups, 0.20D@90 $(\mathrm{t}=-4.99, \mathrm{p}<0.001)$ for the LOW and 0.32D@90 $(z=3.46, p=0.001)$ for the HIGH (Table 1). The oblique component at $135^{\circ}$ of the astigmatism was also overestimated for the $\mathrm{K}_{\mathrm{SIM}}$ in the LOW group 0.11 D @ $135^{\circ}$ $(\mathrm{t}=-2.69, \mathrm{p}=0.02)$ but not in the HIGH, 0.09D @ $135^{\circ}$ $(\mathrm{t}=-2.03, \mathrm{p}=0.06)$.

\section{SIA for HIGH and LOW preoperative astigmatism}

The SIA for each group is represented in Figure 2. The temporal incision resulted in a SE of $0.15 \mathrm{D} @ 90^{\circ}$ ( FE at $\left.180^{\circ}\right)$ for $\mathrm{K}_{\mathrm{SIM}}(\mathrm{t}=2.22, \mathrm{p}=0.04)$ and $0.28 \mathrm{D} @ 90^{\circ}$ for $\mathrm{TCRP}_{3}(\mathrm{t}=2.93, \mathrm{p}=0.009)$ in the HIGH group; however not significant, SE was obtained in the LOW group or for the torque in both groups $(\mathrm{p}>0.05)$.

$\mathrm{FE}$ at $180^{\circ}$ was higher in the HIGH group than in the LOW one, the difference being twice as large with $\mathrm{TCRP}_{3}$ versus $\mathrm{K}_{\text {SIM }}$ (Table 3). An intra-group analysis of $\mathrm{HIGH}$ resulted in an underestimation of the $\mathrm{FE}$ with $\mathrm{K}_{\mathrm{SIM}}$ that amounts to $0.13 \pm 0.27 \mathrm{D}$ compared with the $\mathrm{TCRP}_{3}$ approach $(\mathrm{t}=-2.08, \mathrm{p}=0.05)$.

\section{TCRP at different chords versus $K_{S I M}$}

The Friedman test showed significant differences between $\mathrm{K}_{\mathrm{SIM}}$ and $\mathrm{TCRP}_{3}$ in terms of the preoperative astigmatism. Pairwise comparisons resulted in significant differences for both groups only for $\mathrm{TCRP}_{3}$, whereas in the HIGH group, differences also emerged at lower zone diameters (Figure 3(a)). On the contrary, the preoperative astigmatism's $y$ component showed significant 
Table I. Demographic preoperative data for the LOW and HIGH patient groups.

\begin{tabular}{|c|c|c|c|}
\hline & $\begin{array}{l}\operatorname{LOW}(n=\mid 8) \\
\text { mean } \pm S D \\
\text { median }(I Q R)\end{array}$ & $\begin{array}{l}\mathrm{HIGH}(\mathrm{n}=\mathrm{I}) \\
\text { mean } \pm \mathrm{SD} \\
\text { median }(\mathrm{IQR})\end{array}$ & $P$ value \\
\hline \multirow[t]{2}{*}{ Age (years) } & $63.22 \pm 7.71$ & $59.89 \pm 12.2$ & 0.44 \\
\hline & $63.5(9)$ & $60.5(12)$ & \\
\hline \multirow[t]{2}{*}{ Anterior chamber depth $(\mathrm{mm})$} & $3.25 \pm 0.27$ & $3.35 \pm 0.40$ & 0.40 \\
\hline & $3.19(0.5 I)$ & $3.29(0.58)$ & \\
\hline \multirow[t]{2}{*}{ Axial length (mm) } & $24.01 \pm 1.07$ & $24.63 \pm 1.27$ & 0.12 \\
\hline & $23.82(1.52)$ & $24.76(2.00)$ & \\
\hline \multicolumn{4}{|l|}{ Corneal power (D) } \\
\hline \multirow[t]{2}{*}{$\mathrm{K}_{\mathrm{SIM}}$} & $43.89 \pm 1.47$ & $43.95 \pm 1.70$ & $0.05^{*}$ \\
\hline & $42.73(1.91)$ & $44.25(2.4 I)$ & \\
\hline \multirow[t]{2}{*}{$\mathrm{TCRP}_{3}$} & $42.18 \pm 1.49$ & $43.23 \pm 1.67$ & $0.03^{*}$ \\
\hline & $41.93(2.11)$ & $43.5(1.93)$ & \\
\hline \multicolumn{4}{|c|}{ Corneal astigmatism magnitude (D) } \\
\hline \multirow[t]{2}{*}{$\mathrm{K}_{\mathrm{SIM}}$} & $0.48 \pm 0.21$ & $1.88 \pm 0.94$ & $<0.001 *$ \\
\hline & $0.5(0.23)$ & $1.60(1.15)$ & \\
\hline \multirow[t]{2}{*}{$\mathrm{TCRP}_{3}$} & $0.4 I \pm 0.29$ & $1.86 \pm 0.96$ & $<0.001 *$ \\
\hline & $0.35(0.40)$ & $1.60(1.20)$ & \\
\hline \multicolumn{4}{|l|}{ Preoperative $\mathrm{K}_{\mathrm{SIM}}-\mathrm{TCRP}_{3}(\mathrm{D})$} \\
\hline \multirow[t]{2}{*}{ WTR astigmatism $\left(90^{\circ}\right)$} & $0.20 \pm 0.17^{a}$ & $0.32 \pm 0.27^{a}$ & 0.15 \\
\hline & $0.18(0.20)$ & $0.30(0.23)$ & \\
\hline \multirow[t]{2}{*}{ Oblique astigmatism $\left(135^{\circ}\right)$} & $0.11 \pm 0.18^{a}$ & $0.09 \pm 0.18$ & 0.67 \\
\hline & $0.08(0.13)$ & $0.07(0.28)$ & \\
\hline
\end{tabular}

KSIM: simulated keratometry measured with Pentacam; TCRP : total corneal refractive power at $3 \mathrm{~mm}$ measured with Pentacam; WTR: with-therule astigmatism; IQR: interquartile range; SD: standard deviation.

An independent $t$-test was carried out except for the following comparisons: SD and IQR.

aSignificant differences $(p \leq 0.05)$ emerged between $\mathrm{K}_{\text {SIM }}$ and TCRP 3 paired t-test.

*Significant differences $(\mathrm{p} \leq 0.05)$, independent $t$-test between LOW and HIGH groups.

Table 2.[AQ: 2] Percentage (number) of eyes classified according to the astigmatism type and method of measure.

\begin{tabular}{llll}
\hline & LOW \% (n) & HIGH \% (n) & P value \\
\hline K $_{\text {SIM }}$ & & & \\
WTR & $66.7(12)$ & $66.7(12)$ & 0.54 \\
ATR & $16.7(3)$ & $27.8(5)$ & \\
Oblique & $16.7(3)$ & $5.6(1)$ & \\
TCRP & & & \\
WTR & $44.4(8)$ & $55.6(10)$ & 0.44 \\
ATR & $33.3(6)$ & $38.9(7)$ & \\
Oblique & $22.2(4)$ & $5.6(1)$ & \\
\hline
\end{tabular}

$\mathrm{K}_{\text {SIM: }}$ simulated keratometry measured with Pentacam; $\mathrm{TCRP}_{3}$ : total corneal refractive power at $3 \mathrm{~mm}$ measured with Pentacam; WTR: with-the-rule astigmatism; ATR: against-the-rule astigmatism. Fisher's test performed: $*_{\mathrm{p}} \leq 0.05$.

differences between $\mathrm{K}_{\mathrm{SIM}}$ and TCRP only in the LOW group and below $2 \mathrm{~mm}$ of diameter (Figure 3(c)). There were no statistically significant differences in mean SIA across computing methods $\left(\mathrm{TCRP}_{3}\right.$ vs $\left.\mathrm{K}_{\mathrm{SIM}}\right)$, neither for FE nor for torque in either patient group, and the TCRP location chords in the cornea or the $\mathrm{K}_{\mathrm{SIM}}(\mathrm{p}>0.05)$ (Figure 3(b) and (c)).

\section{Discussion}

\section{Comparison between methods for preoperative astigmatism}

Leube et al. ${ }^{22}$ reported that residual astigmatism could affect the subjective depth of focus. He concluded that with an induced WTR astigmatism of $-0.5 \mathrm{D}$, the depth of focus could be enhanced in the near viewing distance with a marginal loss in binocular visual acuity (VA). The problem arises when a multifocal IOL has been implanted. It has been shown that a given refractive error results in a more pronounced drop in VA and a worsening of visual quality for multifocal IOLs wearers than for those people implanted with monofocal IOLs. ${ }^{23,24}$ It is well known that clear corneal incisions performed during cataract surgery induce changes on corneal astigmatism, whose magnitude depends on factors like size, location, or incision shape. ${ }^{25-29}$ Therefore, to optimize visual performance with multifocal IOLs, SIA should be one of the factors taken into account for IOL selection.

It is well known that each measuring method yields a different corneal astigmatism value. Devices without a Scheimpflug analyzer can overestimate WTR corneal astigmatism. ${ }^{30,31}$ Our study findings are, in this regard, 


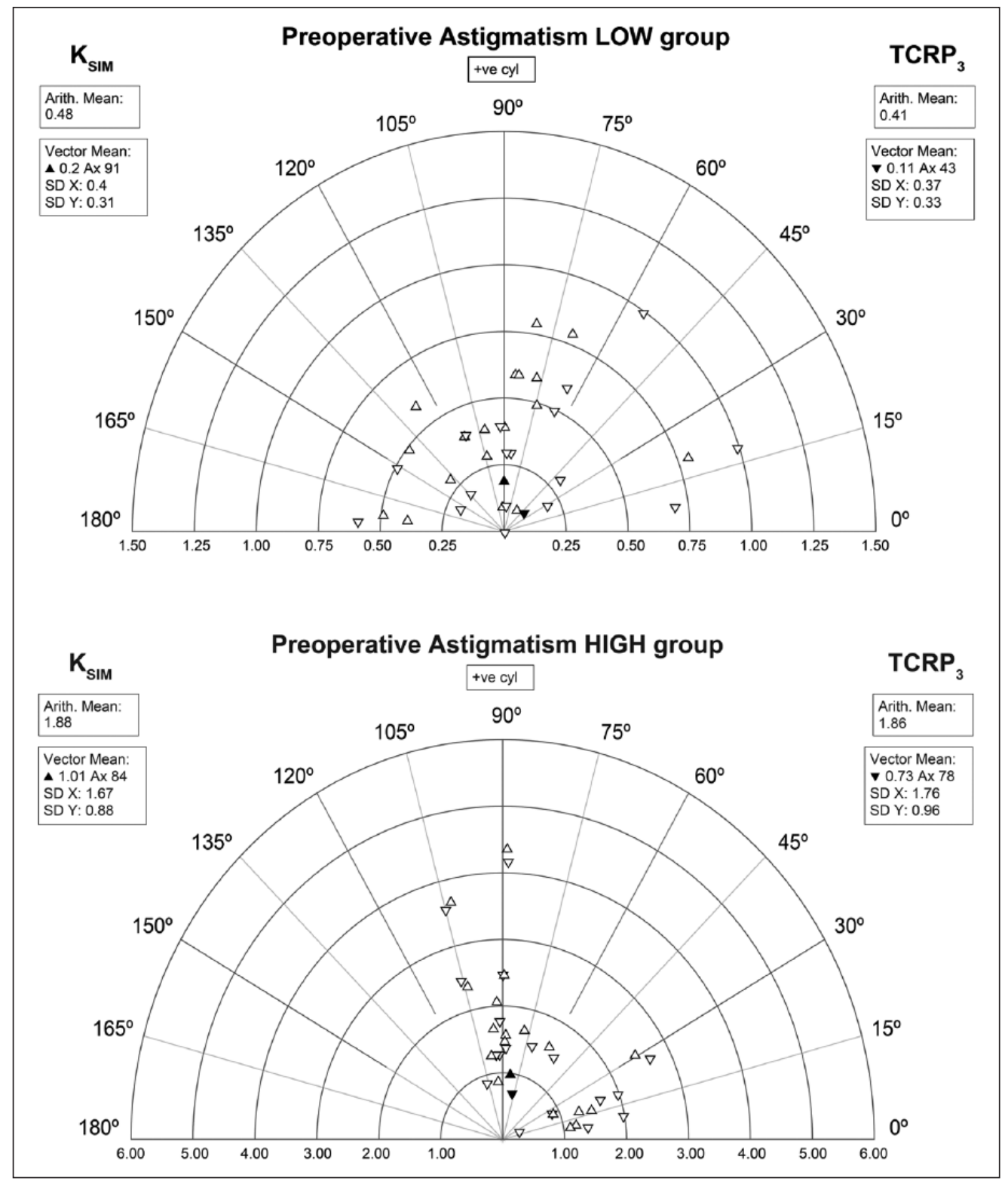

Figure I. Preoperative corneal astigmatism for $\mathrm{K}_{\mathrm{SIM}}$ (up symbols) and $\mathrm{TCRP}_{3}$ (down symbols) for LOW (top) and HIGH (bottom) groups.

wholly in line with Koch et al.'s, ${ }^{30}$ who reported an overestimated preoperative corneal astigmatism with $\mathrm{K}_{\mathrm{SIM}}$ versus TCRP ${ }_{3}$, the difference being larger-despite not being statistically significant-for the higher astigmatism patient group. Our results are also consistent with de Sanctis' ${ }^{\prime 32}$ findings, who also reported greater differences between $\mathrm{K}_{\mathrm{SIM}}$ and TCRP for astigmatism values $\geq 1.0 \mathrm{D}$.

We also evaluated the orthogonal astigmatism components for all the TCRP radial zones versus the preoperative values yielded by $\mathrm{K}_{\mathrm{SIM}}$. Statistically significant differences were found at $3 \mathrm{~mm}$ for the horizontal component (WTR/ ATR). In our opinion, it is important to highlight these differences considering that the $\mathrm{K}_{\mathrm{SIM}}$ value is measured at $3 \mathrm{~mm}$ and that is precisely that value that is used for IOL power calculations. Furthermore, the astigmatism from TCRP at $3 \mathrm{~mm}$ has been proved to be the closest to manifest refractive astigmatism. ${ }^{33,34}$ Those calculations would be particularly relevant for toric lenses and even more for multifocal toric ones.

The preoperative classification of the astigmatism (WTR, ATR, and Oblique) showed a fair agreement between $\mathrm{K}_{\mathrm{SIM}}$ and TCRP ${ }_{3}$ in the LOW group. In addition, the agreement was good according to the Landis criteria ${ }^{35}$ in the HIGH group, despite the fact that $66.7 \%$ of subjects had a WTR astigmatism with $\mathrm{K}_{\mathrm{SIM}}$ that decreased to 


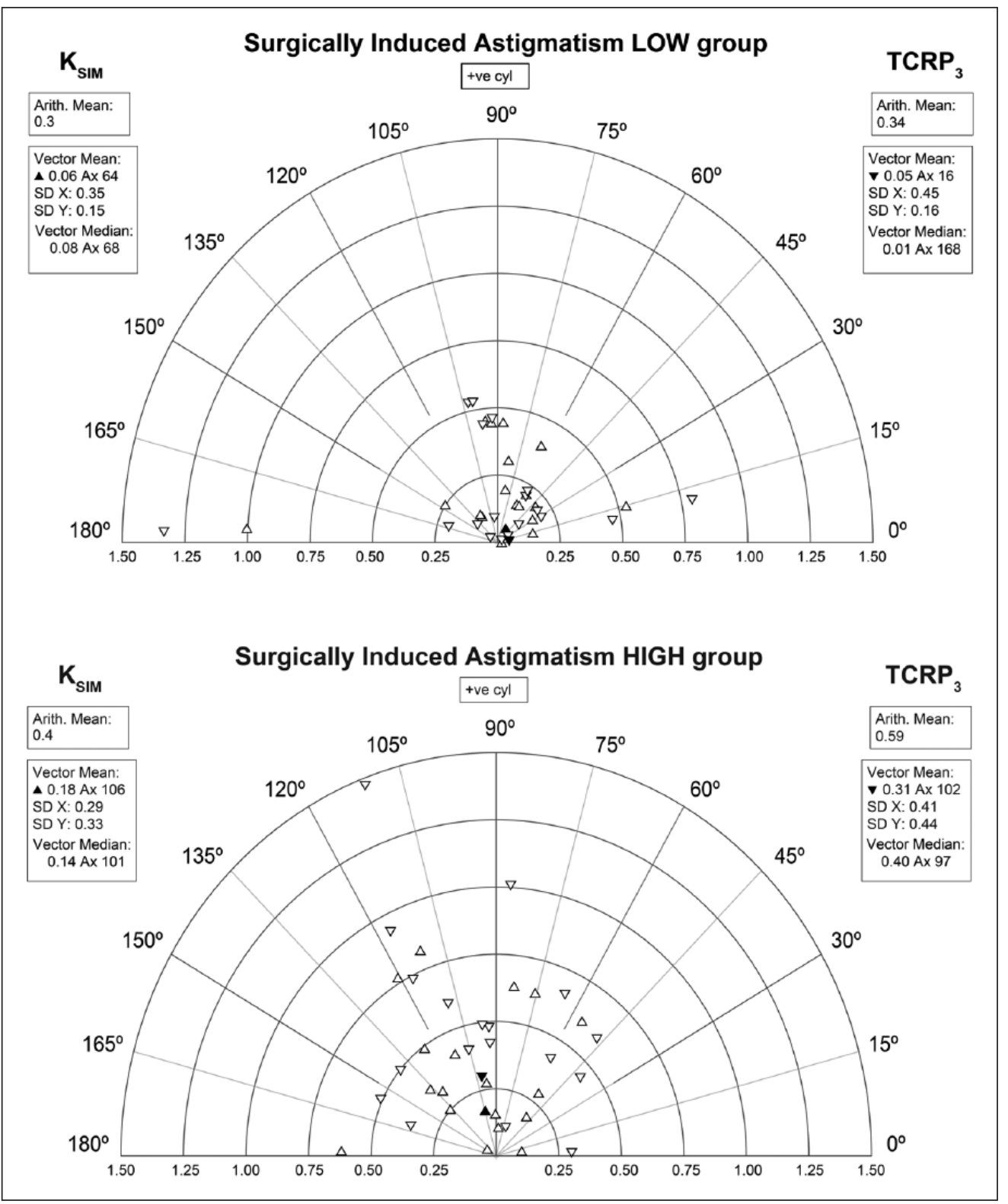

Figure 2. Surgically induced astigmatism for $\mathrm{K}_{\mathrm{SIM}}$ (up symbols) and $\mathrm{TCRP}_{3}$ (down symbols) for LOW (top) and HIGH (bottom) groups.

$55.56 \%$ when the classification was conducted with the $\mathrm{TCRP}_{3}$ astigmatism. These differences in astigmatism classification should be taken into account because it can influence the final results when astigmatism data are divided into groups based on the astigmatism type for the creation of nomograms.

\section{SIA for HIGH and LOW preoperative astigmatism}

As it has been detailed above, differences across devices for astigmatism computation have been widely reported. However, to the best of our knowledge, there are no published studies on SIA including $\mathrm{K}_{\text {SIM }}$ and TCRP at different zones and clearly differentiating between low and high corneal astigmatism. In our study, the incisions were performed in both groups with the same settings and by the same experienced surgeon. The temporal incision resulted in greater FE in the HIGH group, for both $\mathrm{K}_{\mathrm{SIM}}$ and $\mathrm{TCRP}_{3}$, whereas in the LOW group FE was close to zero. Significant differences between the calculation methods were obtained only in the HIGH group for which the FE was underestimated with the $\mathrm{K}_{\mathrm{SIM}}$ compared to the $\mathrm{TCRP}_{3}$ in $0.13 \mathrm{D}$. These results are relevant because they state that low astigmatism values should not be considered when calculating SIA because FE would consequently be 
Table 3. Surgically induced astigmatism (SIA) in the LOW and $\mathrm{HIGH}$ groups for the same clear corneal incision.

\begin{tabular}{llll}
\hline & $\begin{array}{l}\text { LOW }(\mathrm{n}=18) \\
\text { mean } \pm \mathrm{SD} \\
\text { median }(\mathrm{IQR})\end{array}$ & $\begin{array}{l}\mathrm{HIGH}(\mathrm{n}=18) \\
\text { mean } \pm \mathrm{SD} \\
\text { median }(\mathrm{IQR})\end{array}$ & P value \\
\hline $\mathrm{TCP}_{3}$ & & & \\
$\quad$ Flattening effect & $0.04 \pm 0.45$ & $-0.28 \pm 0.4 \mathrm{I}$ & 0.08 \\
& $0.01(0.3 \mathrm{I})$ & $-0.39(0.55)$ & \\
Torque & $0.02 \pm 0.16$ & $-0.12 \pm 0.44$ & 0.19 \\
& $-0.01(0.29)$ & $-0.10(0.60)$ & \\
$\mathrm{K}_{\text {SIM }}$ & & & \\
Flattening effect & $-0.04 \pm 0.35$ & $-0.15 \pm 0.29$ & 0.32 \\
& $-0.06(0.34)$ & $-0.14(0.32)$ & \\
Torque & $0.05 \pm 0.15$ & $-0.10 \pm 0.34$ & 0.10 \\
& $0.06(0.26)$ & $-0.05(0.50)$ & \\
\hline
\end{tabular}

Flattening effect is reported by means of positive values meaning an increase of power and negative a decrease at incision location $\left(180^{\circ}\right)$. Torque is reported by means of negative values meaning orientation to clockwise and positive to counterclockwise.

$\mathrm{K}_{\text {SIM }}$ : simulated keratometry measured with Pentacam; $\mathrm{TCRP}_{3}$ : total corneal refractive power at $3 \mathrm{~mm}$ measured with Pentacam; SD: standard deviation; IQR: interquartile range.

Independent t-test was performed: ${ }^{*} \mathrm{p} \leq 0.05$. underestimated. This finding has been previously reported by Chang et al. ${ }^{36}$ who also found higher SIA for higher preoperative corneal astigmatism. However, Chang et al. ${ }^{36}$ only reported SIA derived from anterior corneal surface and our results additionally suggest that FE can be underestimated in high astigmatism if only anterior cornea is considered instead of the SIA derived from the TCRP .

Previous studies in the literature have reported SIA values computed with $\mathrm{K}_{\mathrm{SIM}}$ and resulting from temporal incisions. Our mean results were lower in the low-astigmatism (LOW) group $(0.06 \mathrm{D})$ than those obtained by Masket et al. ${ }^{26}$ for a $2.2-\mathrm{mm}$ incision $(0.10 \mathrm{D})$ but higher in the high-astigmatism group $(0.18 \mathrm{D})$. In fact, the latter value is very close to that reported by Visser et al. ${ }^{37}$ also in patients with high corneal astigmatism (0.19D). These results only consider the SIA derived from a keratometric index of refraction of 1.3375 , but other authors have also included the contribution of the posterior surface in SIA calculations. For example, Klijn et al. ${ }^{16}$ evaluated single-plane and biplanar corneal incisions, concluding that the SIA of the posterior corneal surface after cataract surgery was of negligible clinical relevance. His study included only low
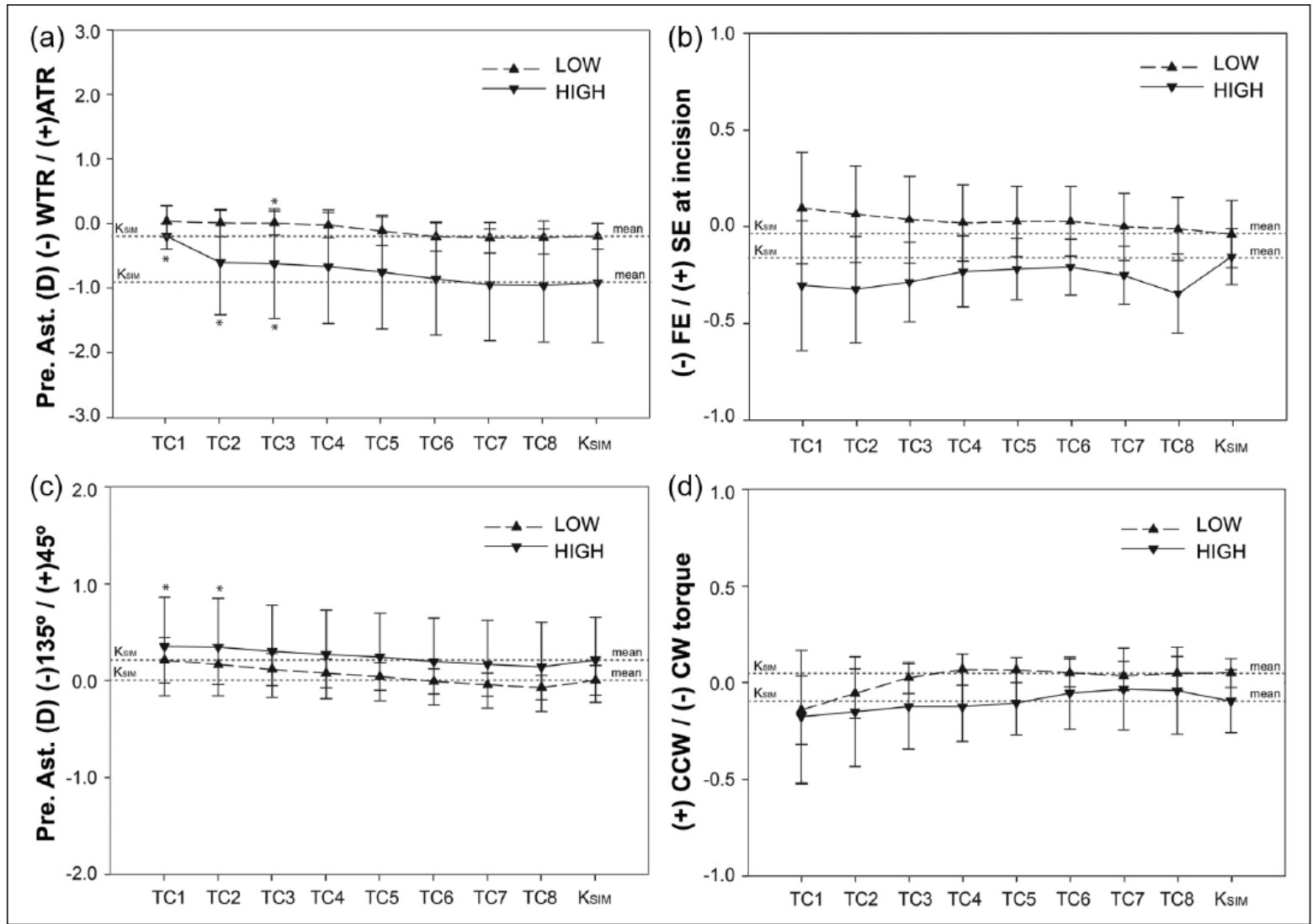

Figure 3. Orthogonal components of the $(a, c)$ preoperative astigmatism and $(b, d)$ flattening/steepening and torque of the SIA in both LOW and HIGH groups. TC indicates those astigmatism components obtained from the total corneal refractive power from the center $(1 \mathrm{~mm})$ to the peripheral $(8 \mathrm{~mm})$ cornea and the number that follows represent $\mathrm{mm}$ from the center. The vertical bars represent $95 \%$ confidence intervals. Asterisks indicate the zones where significant differences were found versus $\mathrm{K}_{\text {SIM }}$, each asterisk at the side of the corresponding group. 
astigmatism patients (i.e. $<1.00 \mathrm{D}$ of anterior astigmatism and $<0.37 \mathrm{D}$ of posterior astigmatism) and the mean power changes were below $0.1 \mathrm{D}$ for both incisions on the posterior surface. Our results support Klijn et al.'s conclusion but only in the low-astigmatism group, where the mean SIA for $\mathrm{K}_{\mathrm{SIM}}(0.04 \mathrm{D})$ was close to TCRP $(0.06 \mathrm{D})$. In this case, SIA is of negligible clinical relevance but not only in the posterior cornea but also in the anterior corneal surface. In addition, the resulting SIA was twice as large with $\mathrm{TCRP}_{3}(0.31 \mathrm{D})$ than with $\mathrm{K}_{\text {SIM }}(0.18 \mathrm{D})$. Therefore, the clinical relevance of the posterior corneal surface is greater among patients who are eligible for toric IOLs.

When the SIA components yielded by TCRP were compared for several corneal zones, there was a trend to be higher and more similar to the SIA for $\mathrm{K}_{\mathrm{SIM}}$ along the $4 \mathrm{~mm}$, although the differences were not statistically significant for any location. However, this comparison between chords should be interpreted with caution because the paired t-test between FE derived from $\mathrm{TCRP}_{3}$ and $\mathrm{K}_{\mathrm{SIM}}$ in the HIGH group resulted in significant differences. This opposition might be due to the non-parametric statistical and post hoc analysis required for multiple comparisons between chords. Our study is mainly limited by its small sample size. More extended studies would be needed, in which incisions located in different positions were created for patients with different sorts of astigmatism.

In conclusion, we evaluated SIA relying on two different methods $-\mathrm{K}_{\mathrm{SIM}}$ and TCRP — and in two subject groups: low-astigmatism patients implanted with spherical trifocal lenses and high-astigmatism ones implanted with toric trifocal ones. We have provided further evidence about how $\mathrm{K}_{\mathrm{SIM}}$ overestimates WTR corneal astigmatism compared to TCRP. However, the most remarkable findings are that SIA was considerably higher in the high-astigmatism group and that $\mathrm{K}_{\mathrm{SIM}}$ seems to significantly underestimate FE. These findings lead to two important considerations: first, only high-astigmatism subjects should be considered for SIA calculation, since mixing their data with that from low-astigmatism patients would result in an underestimation of the FE in temporal clear corneal incisions. Second, the underestimation yielded by $\mathrm{K}_{\mathrm{SIM}}$ suggests that the posterior cornea also is an important contributor to total SIA in subjects with high astigmatism. Moreover, if the posterior surface is dismissed, it would result in an underestimation of the FE. These results should be taken into account when implanting toric lenses.

\section{Declaration of conflicting interests}

The author(s) declared no potential conflicts of interest with respect to the research, authorship, and/or publication of this article.

\section{Funding}

The author(s) received no financial support for the research, authorship, and/or publication of this article.

\section{References}

1. Lindstrom RL. The future of laser-assisted refractive cataract surgery. J Refract Surg 2011; 27(8): 552-553.

2. Javitt JC, Brenner MH, Curbow B, et al. Outcomes of cataract surgery. Improvement in visual acuity and subjective visual function after surgery in the first, second, and both eyes. Arch Ophthalmol 1993; 111(5): 686-691.

3. Ferrer-Blasco T, Montes-Mico R, Peixoto-de-Matos SC, et al. Prevalence of corneal astigmatism before cataract surgery. J Cataract Refract Surg 2009; 35(1): 70-75.

4. Nemeth G, Szalai E, Berta A, et al. Astigmatism prevalence and biometric analysis in normal population. Eur $J$ Ophthalmol 2013; 23(6): 779-783.

5. Koch DD, Ali SF, Weikert MP, et al. Contribution of posterior corneal astigmatism to total corneal astigmatism. $J$ Cataract Refract Surg 2012; 38(12): 2080-2087.

6. Ho JD, Tsai CY and Liou SW. Accuracy of corneal astigmatism estimation by neglecting the posterior corneal surface measurement. Am J Ophthalmol 2009; 147(5): 788-795, 795.e1-795.e2.

7. Reinstein DZ, Archer TJ, Srinivasan S, et al. Standard for reporting refractive outcomes of intraocular lens-based refractive surgery. J Cataract Refract Surg 2017; 43(4): 435-439.

8. Morlet N, Minassian D and Dart J. Astigmatism and the analysis of its surgical correction. Br J Ophthalmol 2001; 85(9): 1127-1138.

9. Altan-Yaycioglu R, Akova YA, Akca S, et al. Effect on astigmatism of the location of clear corneal incision in phacoemulsification of cataract. J Refract Surg 2007; 23(5): 515-518.

10. Altan-Yaycioglu R, Pelit A, Evyapan O, et al. Astigmatism induced by oblique clear corneal incision: right vs. left eyes. Can J Ophthalmol 2007; 42(4): 557-561.

11. Borasio E, Mehta JS and Maurino V. Torque and flattening effects of clear corneal temporal and on-axis incisions for phacoemulsification. J Cataract Refract Surg 2006; 32(12): 2030-2038.

12. Fam HB and Lim KL. Validity of the keratometric index: large population-based study. J Cataract Refract Surg 2007; 33(4): 686-691.

13. Steiner D, Hoffmann P and Goldblum D. Die Berechnung der Intraokularlinsenstarke auf Basis der RaytracingMethoden: ein systematischer Review [The calculation of the intraocular lens power based on raytracing methods: a systematic review]. Klin Monatsbl Augenh 2013; 230(4): 329-332.

14. Garzon N, Poyales F, de Zarate BO, et al. Evaluation of rotation and visual outcomes after implantation of monofocal and multifocal toric intraocular lenses. J Refract Surg 2015; 31(2): 90-97.

15. Nemeth G, Berta A, Szalai E, et al. Analysis of surgically induced astigmatism on the posterior surface of the cornea. J Refract Surg 2014; 30(9): 604-608.

16. Klijn S, van der Sommen CM, Sicam VA, et al. Value of posterior keratometry in the assessment of surgically induced astigmatic change in cataract surgery. Acta Ophthalmol 2016; 94(5): 494-498.

17. Savini G, Barboni P, Carbonelli M, et al. Comparison of methods to measure corneal power for intraocular lens 
power calculation using a rotating Scheimpflug camera. $J$ Cataract Refract Surg 2013; 39(4): 598-604.

18. Wang L, Mahmoud AM, Anderson BL, et al. Total corneal power estimation: ray tracing method versus gaussian optics formula. Invest Ophthalmol Vis Sci 201125; 52(3): 1716-1722.

19. Rodríguez-Vallejo M. Refractive analysis v.1.0.0. A Matlab toolbox for the analysis of refractive results in anterior segment surgery, http://test-eye.com/index.php/en/refractiveanalysis (accessed 2017, 1 September 2017).

20. Alpins NA. A new method of analyzing vectors for changes in astigmatism. J Cataract Refract Surg 1993; 19(4): 524-533.

21. Reinstein DZ, Archer TJ and Randleman JB. JRS standard for reporting astigmatism outcomes of refractive surgery. $J$ Refract Surg 2014; 30(10): 654-659.

22. Leube A, Ohlendorf A and Wahl S. The influence of induced astigmatism on the depth of focus. Optom Vis Sci 2016; 93(10): 1228-1234.

23. Shah S, Peris-Martinez C, Reinhard T, et al. Visual outcomes after cataract surgery: multifocal versus monofocal intraocular lenses. J Refract Surg 2015; 31(10): 658-666.

24. de Vries NE, Webers CA, Touwslager WR, et al. Dissatisfaction after implantation of multifocal intraocular lenses. J Cataract Refract Surg 2011; 37(5): 859-865.

25. Kohnen T, Dick B and Jacobi KW. Comparison of the induced astigmatism after temporal clear corneal tunnel incisions of different sizes. J Cataract Refract Surg 1995; 21(4): 417-424.

26. Masket $\mathrm{S}$, Wang $\mathrm{L}$ and Belani $\mathrm{S}$. Induced astigmatism with 2.2- and 3.0-mm coaxial phacoemulsification incisions. $J$ Refract Surg 2009; 25(1): 21-24.

27. Koc M, Ilhan C, Koban Y, et al. Effect of corneal biomechanical properties on surgically-induced astigmatism and higher-order aberrations after cataract surgery. Arq Bras Oftalmol 2016; 79(6): 380-383.
28. Macarie SS and Macarie DM. Impactul dimensiunii inciziei asupra astigma- tismului indus postoperator [The impact of incisional dimensions on the surgically induced astigmatism]. Oftalmologia 2012; 56(3): 69-72.

29. Marek R, Klus A and Pawlik R. Comparison of surgically induced astigmatism of temporal versus superior clear corneal incisions. Klin Oczna 2006; 108(10-12): 392-396.

30. Koch DD, Jenkins RB, Weikert MP, et al. Correcting astigmatism with toric intraocular lenses: effect of posterior corneal astigmatism. J Cataract Refract Surg 2013; 39(12): 1803-1809.

31. Jing Q, Tang Y, Qian D, et al. Posterior corneal characteristics of cataract patients with high myopia. PLOS ONE 2016; 11(9): e0162012.

32. de Sanctis U, Donna P, Penna RR, et al. Corneal astigmatism measurement by ray tracing versus anterior surfacebased keratometry in candidates for toric intraocular lens implantation. Am J Ophthalmol 2017; 177: 1-8.

33. Qian Y, Liu Y, Zhou X, et al. Comparison of corneal power and astigmatism between simulated keratometry, true net power, and total corneal refractive power before and after SMILE surgery. J Ophthalmol 2017; 2017: 9659481.

34. Davison JA and Potvin R. Refractive cylinder outcomes after calculating toric intraocular lens cylinder power using total corneal refractive power. Clin Ophthalmol 2015; 9: 1511-1517.

35. Landis JR and Koch GG. The measurement of observer agreement for categorical data. Biometrics 1977; 33(1): 159-174.

36. Chang SW, Su TY and Chen YL. Influence of ocular features and incision width on surgically induced astigmatism after cataract surgery. J Refract Surg 2015; 31(2): 82-88.

37. Visser N, Ruiz-Mesa R, Pastor F, et al. Cataract surgery with toric intraocular lens implantation in patients with high corneal astigmatism. J Cataract Refract Surg 2011; 37(8): 1403-1410. 